\title{
LETRAMENTO COMO ESTRATÉGIA DE FORMAÇÃO PARA A AUTONOMIA: OS PRIMEIROS PASSOS DE UM PROJETO DE EXTENSÃO EM MOVIMENTO
}

\author{
Karine Goulart Schneider ${ }^{1}$, Ana Paula Mendes ${ }^{2}$, Daniela Arns Silveira ${ }^{3}$, Ricardo Luiz de \\ Bittencourt $^{4}$
}

\begin{abstract}
RESUMO
As dificuldades de leitura e interpretação dos estudantes brasileiros vêm sendo apontadas pelos sistemas de avaliação da educação básica como desafio a ser superado pelas políticas públicas de educação. Cabe ressaltar ainda, nesse caso, os chamados analfabetos funcionais, aqueles sujeitos com níveis de leitura que não alcançam a compreensão e interpretação. Esse estudo trata dos primeiros passos de reflexão sobre as práticas a serem desenvolvidas no Projeto de Extensão Letramento como uma estratégia de formação para a autonomia, o qual propõe a alfabetização a partir do letramento aos funcionários com baixo nível de escolaridade da Universidade do Extremo Sul Catarinense. Nesse artigo, buscar-se-á ressaltar discussões que permeiam a formação do professor, a extensão e a comunicação durante a graduação e a perspectiva sobre a alfabetização, bem como seus fundamentos. Trata-se de resultado prévio de uma pesquisa bibliográfica qualitativa, realizada pelo grupo responsável pelo projeto, a fim de subsidiar teoricamente a aplicabilidade dessa atividade, tendo como principais bases teóricas Brandão (1989), Freire (1992), Goulart (2006) e Kleiman (1995). Com esse estudo, almeja-se apresentar as possibilidades da construção do pensamento crítico numa perspectiva de educação libertadora bem como pensar em possibilidades de formação de professores.
\end{abstract}

Palavras-chave: Extensão; Letramento; Autonomia; Formação de professores.

\begin{abstract}
The difficulties of reading and interpretation of Brazilian students have been pointed out by the systems of evaluation of basic education as a challenge to be overcome by public education policies. It is also worth mentioning, in this case, the so-called functional illiterates, those subjects with levels of reading that do not reach understanding and interpretation. This study deals with the first steps of reflection on the practices to be developed in the Extension Literacy Project as a training strategy for autonomy, which proposes literacy based on the literacy of the low level of education employees of the UNESC. In this article, we will try to highlight discussions that permeate the teacher's formation; Extension and communication during graduation and the perspective on literacy as well as its foundations. It is a previous result of a qualitative bibliographical research carried out by the group responsible for the project, in order to theoretically subsidize the applicability of this activity, having as main

\footnotetext{
${ }^{1}$ Graduanda do curso de Letras e extensionista no Projeto de Extensão Letramento como estratégia de formação para a autonomia. E-mail: kaka_schneider@hotmail.com.

${ }^{2}$ Graduanda do curso de Letras e extensionista no Projeto de Extensão Letramento como estratégia de formação para a autonomia.

${ }^{3}$ Graduada em Letras. Mestre em Ciências da Linguagem. Coordenadora do Projeto de Extensão Letramento como estratégia de formação para a autonomia.

${ }^{4}$ Graduado em Pedagogia. Doutor em Educação. Orientador do Projeto de Extensão Letramento como estratégia de formação para a autonomia.
} 
theoretical bases Brandão (1989), Freire (1992), Goulart (2006) and Kleiman (1995). With this study, we aim to present the possibilities of the construction of critical thinking in a perspective of liberating education as well as thinking about possibilities of teacher training.

Keywords: Extension; Literacy; Autonomy; Teaching Training. 


\section{INTRODUÇÃO}

O Projeto de Extensão intitulado Letramento como estratégia de formação para a autonomia foi homologado pelo edital $\mathrm{n}^{\circ}$ 01/2016/UNAHCE e posteriormente aprovado pela Universidade do Extremo Sul Catarinense (UNESC), a qual tem como fundamento o ensino, a pesquisa e a extensão, possibilitando, assim, a feitura de estudos como esse, a atender a comunidade de forma que concilie os três princípios a fim de auxiliar na necessidade da mesma. Percebe-se aqui mais um dos seus propósitos, como comunitária, uma vez que se está atendendo ao público externo, mas diretamente ligado à academia, por conta de seu vínculo empregatício.

Esse artigo surge da participação, das leituras e das reflexões das extensionistas desse projeto, o qual se trata de uma proposta interdisciplinar, cuja atuação se dará a partir de dois cursos de licenciatura - Letras e Pedagogia -, numa perspectiva de integração entre o que se estuda na teoria e o que se pode fazer na prática. Podemos afirmar que ambos os cursos contemplam a ideia de letramento no sentindo de compreender as necessidades dos futuros educandos.

A intenção foi, então, olhar para a comunidade externa vinculada à UNESC, a saber funcionários das mais diversas áreas, acerca da sua formação escolar, haja vista uma defasagem notória em seu grau de instrução. Há funcionários analfabetos, semianalfabetos, com ensino fundamental incompleto, por exemplo. Neste sentido é que esta proposta de extensão se apresenta, com o intuito de trabalhar a leitura e a produção textual em nível de letramento, cuja intencionalidade não é, a curto prazo, promover uma "escola de alfabetização", mas um espaço de aprimoramento das linguagens com foco no letramento literário, considerando, principalmente, o contexto dos envolvidos.

Este artigo trata de uma pesquisa bibliográfica qualitativa, a qual tem como sua principal base teórica o educador Freire. Será abordada a ação da extensão e da comunicação, vinculada à formação de professores; a perspectiva freireana da alfabetização e seus princípios e orientações. Autores como Brandão (1989), Freire (1992; 1996; 2003; 2008; 2011), Goulart (2006) e Kleiman (1995) também acompanham as reflexões colocadas em movimento nesse artigo.

O artigo está organizado inicialmente com reflexões sobre a formação de professores, a extensão e a comunicação. Posteriormente, se discute a perspectiva freireana de alfabetização e, por fim, os princípios orientadores da atividade de ensino e extensão sob a ótica de Freire. 


\section{REFLEXÕES SOBRE A FORMAÇÃo DE PROFESSORES, A EXTENSÃo E A COMUNICAÇÃO}

A formação de professores é um processo complexo que se constitui a partir de diversos fatores, dentre os quais, a necessária articulação entre ensino, pesquisa e extensão. Com esse entendimento, pretende-se estabelecer reflexões sobre a formação de professores e extensão/comunicação.

Por muito tempo, durante o século XX, a formação de professores foi prejudicada pelo tecnicismo, o qual priorizava a produção e a habilitação da grande escala de mão-de-obra, colocando, assim, em último plano, a qualidade do ensino docente. Esse fato gerou não só um déficit enorme na formação dos alunos, como também o esquecimento daqueles à margem da sociedade (SENNA, 2008).

Já no século XXI "o magistério começa, a partir daí, a resgatar sua natureza fundamentalmente social e humanista, abraçando como um dever ético a causa da inclusão das minorias sociais" (SENNA, 2008, p. 210). Do mesmo modo, tornou-se fundamental um novo olhar diante da graduação do professor, a fim de possibilitar uma aproximação da realidade na qual ele irá atuar.

Segundo Senna (2008), a nova formação da docência toma como princípio a constituição de um leitor de mundo o qual será instigado a ser um pesquisador de seu contexto, aproximando-se das minorias sociais, a fim de realmente tornar a acontecer a inclusão social. Nóvoa (2012, p. 13) completa que na formação docente é fundamental a experiência, a qual especifica em:

Experiências essas em relação com o conhecimento, experiências em relação a investigação, mas que são experiências também na relação com a cultura, na relação com a sociedade, no conjunto de compromissos, que sem os quais ninguém se forma um estudante universitário.

Desse modo, discutir os processos formativos que constituem o professor requer o olhar para a extensão como atividade acadêmica, sendo assim, cabe aqui estabelecer o conceito de extensão. Segundo Freire (1992, p. 20), a significância do vocábulo é dependente do contexto no qual é inserido, neste caso, a ação extensionista é "a de quem estende algo até alguém”, esse ‘algo' é referente aos conhecimentos e técnicas do educador, e o alguém seria o educando.

Esmiuçando a palavra 'estender', é notável que, ao realizar essa ação, torna-se o indivíduo receptivo um paciente, pois ele não participa da construção do conhecimento, mas aceita e toma para si o estendido, isto é, a posição e voz do extensionista. Percebem-se, aqui, ainda as raízes do tecnicismo. Freire (1992) nomeia esse ato como 'domesticação' e 
complementa que essa atividade provoca uma invasão cultural, a qual impõe os conhecimentos cientificistas, considerados importantes pelo educador, e menospreza o conhecimento prático vivenciado pelo educando. O primeiro introjeta conteúdos mecanicamente no segundo, e esse, que já está tão afetado por desacreditar em sua capacidade, aceita essa relação extensionista sem relutância.

Visando ao princípio de uma educação libertadora e uma formação docente inclusiva, adotaremos neste projeto uma relação de comunicação. Para isso, é preciso entendê-la profundamente, mas primordialmente é importante ressaltar que o educador deve se estabelecer no mesmo lugar que o educando, pois "é preciso que quem sabe saiba sobretudo que ninguém sabe tudo e que ninguém tudo ignora” (FREIRE, 2011, p. 39). Do mesmo modo, o conhecimento prático é tão importante quanto o científico.

A comunicação se dará a partir do diálogo com os participantes, os quais, de acordo com Freire (1992, p. 49), estão em uma estrutura fechada no antidiálogo e apresentam uma forte resistência e "esta atitude é de desconfiança também de si mesmos. Não estão seguros de sua própria capacidade. Introjetam o mito de sua ignorância absoluta. É natural que prefiram não dialogar". Cabe ao extensionista valorizar todo o tipo de conhecimento e potencializar o educando a dialogar com assuntos de seu meio. Uma das principais razões para que aconteça o diálogo é, segundo Freire (1992, p. 68),

\begin{abstract}
a de diminuir a distância entre a expressão significativa do técnico e a percepção pelos camponeses em torno do significado. Deste modo, o significado passa a ter a mesma significação para ambos. E isto só se dá na comunicação e intercomunicação dos sujeitos pensantes a propósito do pensado, e nunca através da extensão do pensado de um sujeito até o outro.
\end{abstract}

Para alcançar a compreensão mútua sobre o pensado de cada sujeito a linguagem comunicativa de ambos deve ser a mesma, assim, se o extensionista utilizar uma linguagem tecnicista, dificilmente o indivíduo receptor o entenderá, o que acarreta no princípio que Freire defende, já citado aqui, de que o educador tem de estar em uma relação horizontal com seu educando para que de fato aconteça a comunicação.

O conceito e a aplicação da comunicação na formação docente são a oportunidade da aproximação do graduando com as minorias sociais, há muito tempo já esquecidas, as quais lutam por sua autonomia diante de uma sociedade letrada. Essa experiência torna a graduação mais completa e acarreta na boa atuação posterior do docente na sala de aula, o qual é inspirado a levar conceitos, e até mesmo, a própria relação de comunicação para com seus alunos, unindo-os a eles para a construção de conhecimento, aprendendo tanto quanto 
ensinando, trocando seus próprios pensados sobre o mesmo objeto e a partir de ali gerar uma nova problematização.

Como esse projeto trata também da alfabetização dos educandos, é necessário estabelecer a perspectiva a ser adotada para a aplicabilidade da mesma. A atividade de comunicação deve ser levada em consideração como um fundamento norteador ao longo desse artigo.

\section{A PERSPECTIVA FREIREANA DE ALFABETIZAÇÃo}

A leitura, nas suas mais variadas formatações, bem como a produção escrita, dentro dos mais diferentes gêneros existentes, é capaz de promover a integração do indivíduo no mundo do qual faz parte, embora, muitas vezes, não se sinta assim. Trabalhar com o letramento, numa perspectiva de processo de alfabetização, vai além do ler e escrever, uma vez que possibilita o acesso a diferentes áreas do conhecimento e do saber, inclusive saberes populares, tão ricos em nossa sociedade.

O trabalho com o processo de letramento que aqui se coloca entende que é possível desenvolverem-se as habilidades e competências dos indivíduos envolvidos, cuja atuação no meio social será sutilmente observada, pois se estará lidando com a formação e a comunicação interpessoal, procurando a integralização de seus saberes à sua constituição de sujeito letrado, agente crítico, emancipado, partícipe de sua comunidade, conhecedor de seus direitos e deveres efetivamente. A busca pela transformação político-social e pessoal é possível a cada encontro.

Isto posto, além de se oferecer uma formação própria para o público interno, que é da comunidade externa (ressaltando a função social de universidade comunitária), contribui-se para o crescimento pessoal do indivíduo diretamente envolvido, bem como se eleva a sua autoestima, seu desenvolvimento de leitura - literária e de mundo. Para além da formação, o Projeto lida com o pessoal, com a capacidade de interação do indivíduo junto à comunidade em que está inserido, uma vez que permite o contato íntimo com as letras e toda a sua dimensão cultural e social. É o caráter humanitário da universidade acontecendo dentro do seu próprio espaço, promovendo satisfação pessoal e maior autonomia aos envolvidos, os quais vivem num mundo cada vez mais letrado, de todas as formas.

A educação para jovens e adultos, como se apresenta nesta proposta, tem respaldo nas ideias defendidas por Freire, o qual não acreditava no uso convencional da cartilha, com um aprendizado mecânico, a partir de mera repetição ou textos artificiais, distantes da realidade social e econômica dos envolvidos. Segundo Freire (1996), é preciso considerar o que o 
sujeito traz consigo, no sentido de fazer uso deste conhecimento e a partir dele construir-se um caminho para o processo ensino-aprendizagem, o qual deve ser libertador, uma vez que se entende que se quer uma educação capaz de formar um sujeito autônomo e não mais oprimido.

O conhecimento, assim como o próprio ser humano, é algo inacabado. De acordo com Freire, ainda, está-se constantemente buscando novos conhecimentos, por meio da curiosidade, que é do próprio homem, e de todas as implicações que esta gera, como senso de ética, de respeito pelo outro, de criticidade, de ruptura com o que está posto, cujo propósito é o de construir conhecimento e não transferir. Aí está o desafio da educação e, por que não, deste projeto de extensão.

É importante salientar que, segundo o Censo de 2010, fornecido pelo Instituto Brasileiro de Geografia e Estatística (IBGE, 2010), a taxa de analfabetismo ainda é grande em algumas regiões do Brasil, apesar de ter havido uma diminuição de 12,8\% para $9 \%$ o número de pessoas que ainda não saber ler e escrever. Assim, embora não esteja na região Sul boa parte desses números, há dentro da nossa universidade um público que contribui para este resultado, além de alguns outros que corroboram para o índice dos analfabetos funcionais. Pretende-se, portanto, atender a este público, oferecendo-lhes, dentro do espaço da universidade, onde estão se formando futuros professores, inclusive, além de caracteristicamente ser um ambiente de criticidade, liberdade de expressão e pensamento, discussão sobre as mais variadas situações e condições sociais, econômicas e culturais da comunidade, um momento de contato com as letras, em diferentes enfoques, de variadas formas de linguagem, a partir de diferentes gêneros, com um olhar para as práticas de letramento, as quais, de acordo com Rojo (2009), vão sendo exercidas em diferentes contextos e vão se constituindo em níveis de alfabetismo ou de desenvolvimento de leitura e escrita.

Refletindo que "a verdadeira natureza do letramento são as formas que as práticas de leitura e escrita concretamente assumem em determinados contextos sociais, e isso depende fundamentalmente das instituições sociais que propõem e exigem essas práticas" (SOARES, 1998 apud GOULART, 2006, p. 458), acredita-se que seja uma oportunidade de oferecer uma atividade extensionista que propõe a ampliação do letramento para a comunidade, que é externa (afinal são funcionários contratados), dentro do espaço da universidade, com vistas a se olhar para o ambiente de trabalho, que é um ambiente educacional, propiciando, assim, que seja também seu ambiente de estudo. Para além disso, crê-se, parafraseando Antunes (2010), que todos podem, de alguma forma, se beneficiar dos diferentes recursos e/ou estratégias usados para a produção de um texto escrito. Para além da educação, é uma questão de 
inclusão social e de emancipação! O projeto busca promover o letramento linguísticoliterário, com vistas à alfabetização em diferentes contextos, a partir de diversos gêneros, focalizando a formação do indivíduo emancipado.

O projeto é voltado para os funcionários analfabetos e com baixo grau de escolaridade que trabalham na Universidade do Extremo Sul Catarinense (UNESC), nos cargos de auxiliar de serviços gerais, manutenção predial e copa. O que exige, portanto, um acolhimento maior e mais natural possível para que todos se sintam confortáveis com a nova proposta. Para isso, serão necessários princípios a serem seguidos, com o intuito de facilitar a compatibilidade entre educador e educando, para, assim, chegarem à autonomia idealizada.

\section{PRINCÍPIOS ORIENTADORES DA ATIVIDADE DE ENSINO E EXTENSÃO SOB A ÓTICA DE FREIRE}

Iniciar qualquer trabalho que envolva o compartilhamento e a troca de conhecimentos requer saber como fazer esse movimento de modo que ambas as partes saiam envolvidas em novas descobertas. O saber fazer certo enquanto essas atividades estão sendo confeccionadas é o ter consciência que "educar é uma tarefa de troca entre pessoas" (BRANDÃO, 1989, p. 22) e essa troca se dará quando o educador, aquele que vai para "influenciar" o educando, tende a agir com maestria. Esse movimento pode ser feito quando o primeiro toma a relação "mundo/educando" como base para seu projeto. Freire (2008) diz que antes da leitura da palavra é preciso a leitura do mundo; o meio social no qual o educando está inserido.

É nessa perspectiva de educação extensionista que o projeto se desenrolará. Com influência metodológica de Freire, pretende-se fazer primeiramente uma base de conhecimentos sobre os educandos envolvidos; suas histórias, suas referências, brevemente seus saberes e intitular todas essas informações como o conjunto primordial para encaminhálos adiante no processo.

Além disso, é necessário reconhecer o educando não como estoque de informações, mas inteiramente o contrário disso, como um possuidor de inúmeros e grandiosos conhecimentos, esses importantíssimos para a construção de seu letramento. Freire ressalta que

O educador, como quem sabe, precisa reconhecer, primeiro, nos educandos em processo de saber mais, os sujeitos com ele, deste processo e não pacientes acomodados; segundo, reconhecer que o conhecimento não é um dado aí, algo imobilizado, concluído, determinado, a ser transferido por quem o adquiriu a quem ainda não o possui (FREIRE, 2008, p. 28). 
Diante disso, é visto que todo conhecimento já possuído pelo educando valerá para o aprimoramento na construção da sua leitura e escrita. No sistema de alfabetização a ser usado, influenciado por Freire, entende-se que é necessário partir desse pressuposto, sabendo que algo já familiarizado facilitará a entrada na compreensão do processo. Podemos intitular essa parte de reconhecimento dos educandos, como a primeira parte do projeto. Feita essa etapa, partir-se-á para outra, que basicamente, segundo Brandão (1989), é obter as palavras geradoras; essas são as palavras em maior destaque ou que mais se encaixam na realidade dos mesmos. É sabido que todo esse processo é feito de maneira abrangente, pois eles serão "alfabetizados de dentro para fora" (BRANDÃO, 1989, p. 18), de forma que tudo a ser iniciado será de consciência própria.

A etapa seguinte é totalmente dependente da anterior no quesito conhecimento, pois após a obtenção das palavras, serão introduzidos os temas geradores, associando, assim, os vocábulos já aprendidos a assuntos que cabem na relação. Gerarão discussões e elaborarão a apreensão do máximo possível de senso crítico. Isso para clarear o instinto curioso dos educandos, que, como tudo, só aprimorará seus saberes. Conforme Freire (1992), para isso, é preciso um sujeito curioso em referência ao mundo. Essa flexibilidade crítica que se pretende enaltecer com os educandos é também uma forma de "reflexão sobre a própria alfabetização" (BRANDÃO, 1989, p. 49) a qual facilitará a próxima etapa do processo. Essa se dará com a desconexão das pequenas "partes" das palavras, para, assim, mostrar aos educandos que é possível a formação de novas palavras a partir da junção diferenciada dessas "partes". Mas essa etapa não será mera absorção de regras, mas feito de maneira que o estudante tenha consciência própria de como é possível essa nova construção de vocábulos. Vale ressaltar que essa grande etapa inicial do processo de alfabetização não será sequencialmente seguida de modo explícito como destacado aqui, pois se valerá muito do tempo que todos os educandos levarão para a adaptação. Os extensionistas, como parte importante da alfabetização, farão o papel de educadores e "a tarefa do educador é, antes de mais nada, a de criar uma outra educação" (BRANDÃO, 1989, p. 85) e isso será válido com suas respectivas avaliações de evolução dos educandos. Caso seja preciso, moldar-se-á a metodologia.

A comunicação entre educador e educando também é parte importante no projeto de letramento; ela não pode dar-se verticalmente, mas sim horizontalmente, de maneira que todos se comuniquem por igual. Freire (1992) entende que a educação é por si comunicação, diálogo, uma busca e um encontro de significados, tratando, assim, a comunicação como algo indispensável. Todo ato de comunicação exige, portanto, um ato de pensar e esse ato de pensar faz o raciocínio crítico do sujeito ser aperfeiçoado; e tornar educandos em seres 
críticos e pensantes é uma das metas. De acordo com Freire (1992, p. 66), "todo ato de pensar exige um sujeito que pensa, um objeto pensado, que mediatiza o primeiro sujeito do segundo e a comunicação entre ambos, que se dá através de signos linguísticos”. Assim, é preciso de um sujeito e de um objeto, o primeiro é o educando e o segundo suas leituras de mundo; logo, realizar-se-á a leitura da palavra, totalmente integrada ao processo de alfabetização.

Do mesmo modo, os extensionistas compartilharão seus saberes com os conhecimentos de seus educandos, trabalhando a troca e problematizando criticamente suas novas descobertas. É válido dizer que indiferente de como trabalharem, no tempo que essa tarefa levará, os educadores não irão "concluir" o ensino nesse projeto de letramento, mas sim encaminhar, até certo ponto, aquilo que conseguirem no tempo de seus educandos, priorizando ao máximo a qualidade de aprendizagem.

É preciso, então, a princípio, entender que nenhum sujeito em processo de aprendizagem inicial, nesse caso especificamente, esteja totalmente vazio e, assim, seja necessário preenchê-lo com um "conhecimento" concluído. Freire (2008) enfatiza a importância do sujeito potencializando-o como "meio/ferramenta" indispensável na tarefa de alfabetizar; que não se educa um sujeito sem que ele seja parte ativa e presente no ato de educar.

A alfabetização de adultos é um trajeto aparentemente pouco trilhado, e, por isso mesmo, é tão importante a qualidade libertadora que os graduandos tendem a ter para andarem nesse caminho. Quando Freire trata desse assunto em seus textos, é visível a preocupação com tal qualidade; "me parece interessante reafirmar que sempre vi a alfabetização de adultos como um ato político e um ato de conhecimento, por isso mesmo como um ato criador" (2008, p. 19). Ato criador que se molda conforme a necessidade deles se apresenta, transformando e aperfeiçoando a maneira de aprender. O tempo dessa transformação não tem prazo, pois o homem se constrói e reconstrói ao longo da vida, não há questionamento de tempo porque "não há que considerar perdido o tempo do diálogo que, problematizando, critica e, criticando, insere o homem em sua realidade como verdadeiro sujeito da transformação" (FREIRE, 1992, p. 51). E comunicação, como já indicado, é o ato de pensar, que leva ao ser um senso crítico, construindo, assim, um conhecimento que se regenera a todo tempo.

\section{CONSIDERAÇÕES FINAIS}

Em suma, esse estudo apresentou os primeiros passos de um projeto de extensão em andamento, os quais se deram a partir de leituras e discussões a fim de entender conceitos e 
estabelecer princípios a serem seguidos. Buscou-se consolidar a comunicação partindo da necessidade dos educandos e não de um roteiro a ser seguido, possibilitando sempre ser alterado conforme o contexto estabelecido.

Sabendo que a comunidade já é dotada por saberes próprios, a atividade toma como um dos objetivos principais a qualidade do ensino e não a rapidez ou a quantidade do mesmo. Nenhum tempo é utilizado em vão, pois toda discussão e reflexão possibilita a construção de novas ressignificações sobre o vivido e o redirecionamento das práticas de ensino e de extensão.

Acrescentado a um meio comunitário que respira educação, o projeto de comunicação se completa em intenções grandiosas de uma prática educativa renovada, libertadora, que procura sempre garantir o pensamento crítico dos educandos, para auxiliar na sua transformação de grandes pensadores e pesquisadores de "mundo". Vale salientar que não se espera um método prático e finito, mas, pelo contrário, uma construção de saberes colhidos dos que buscam conhecimento e autonomia.

O presente artigo proporcionou reflexões necessárias à compreensão da atividade de extensão como comunicação, como sugere Freire, bem como a compreensão da importância dos processos de alfabetização e letramento para a construção da autonomia. Assim, as atividades de extensão e comunicação fortalecem a formação de professores e o projeto de universidade comunitária que se compromete com a formação do cidadão crítico e autônomo.

\section{REFERÊNCIAS}

ANTUNES, I. Análise de textos: fundamentos e práticas. São Paulo: Parábola, 2010.

BRANDÃO, C. R. O que é o método Paulo Freire. 15. ed. São Paulo: Brasiliense, 1989.

FREIRE, P. A importância do ato de ler: em três artigos que se completam. 49. ed. São Paulo: Cortez, 2008.

FREIRE, P. A importância do ato de ler: em três artigos que se completam. 51. ed. São Paulo: Cortez, 2011.

FREIRE, P. Educação como prática da liberdade. Rio de Janeiro: Ed. Paz e Terra. 27. ed. 2003.

FREIRE, P. Extensão ou comunicação? 10. ed. Rio de Janeiro: Paz e Terra, 1992.

FREIRE, P. Pedagogia da autonomia: saberes necessários à pratica educativa. 39. ed. São Paulo: Paz e Terra, 1996.

GOULART, C. Letramento e modos de ser letrado: discutindo a base teórico-metodológica de um estudo. Revista Brasileira de Educação, v. 11, n. 33, set./dez. 2006.

IBGE. Censo Demográfico 2010 - Disponível em: <http://censo2010.ibge.gov.br/>. Acesso em: 15 jul. 2016. 
KLEIMAN, A. B. Os significados do letramento: uma nova perspectiva sobre a prática social da escrita. Campinas: Mercado de Letras, 1995.

NOVOÀ, A. Pedagogia Universitária: já estamos no século XXI ou ainda não?. VII Congresso Iberoamericano de Docência Universitária - Ensino Superior: Inovação e qualidade na docência. São Paulo, 2012.

ROJO, R. H. R. Letramentos múltiplos, escola e inclusão social. São Paulo: Parábola, 2009.

SENNA, L. A. G. Formação docente e educação inclusiva. Cadernos de Pesquisa, Rio de Janeiro, v. 38, n. 133, p. 195-219, Jan/abril 2008. 